\title{
REVISIÓN
}

\section{Interacción bacteria-microalga en el ambiente marino y uso potencial en acuicultura}

\author{
Microalgae and bacteria interaction in the aquatic environment and \\ their potential use in aquaculture
}

CARLOS E. RIQUELME \& RUBÉN E. AVENDAÑO-HERRERA ${ }^{1}$

${ }^{1}$ Laboratorio de Ecología Microbiana, Departamento de Acuicultura, Universidad de Antofagasta. Casilla 170, Antofagasta, Chile; e-mail: criquelme@uantof.cl

\begin{abstract}
RESUMEN
El presente estudio tiene como objetivo revisar el conocimiento generado sobre el rol que juegan las interacciones bacteria-microalga en ambientes marinos y dulceacuícolas, definiendo las posibles aplicaciones que puede tener el conocimiento de estas interacciones en el manejo de las aguas costeras y sistemas acuícolas. Los antecedentes proporcionados en este análisis permiten sugerir que bacterias y/o microalgas, constituyen una alternativa para el control de proliferaciones de bacterias y fitoplancton causantes de efectos dañinos en ambientes naturales y sistemas cerrados de cultivo. Además, las interacciones específicas entre bacteriamicroalga permitiría la optimización de sistemas productivos en la industria acuícola. Sin embargo, los mecanismos de estas interacciones son pobremente entendidos. Futuras investigaciones debieran ser dirigidas a comprender el modo de acción de las interacciones bacteria-microalga a nivel molecular.
\end{abstract}

Palabras clave: interacción, bacterias, microalgas, "bloom” fitoplanctónico, acuicultura.

\section{ABSTRACT}

The objective of this survey is to review the knowledge generated with respect to the role of bacteriamicroalgae interaction play in marine and fresh environments, and to define the possible application of these microorganisms on the management of costal water and aquaculture systems. This review proposes that bacteria and/or microalgae are an alternative to control the proliferation of bacteria and phytoplankton that cause damages in natural environments or in closed culture systems. Also, the knowledge of specific interactions between bacteria and microalgae will allow the optimization of productive systems in aquaculture. However, until date the mechanisms involved in these interactions are poorly understood. Therefore, future investigations should be directed towards understanding the mode of action of such interactions at a molecular level.

Key words: interaction, bacteria, microalgae, phytoplankton bloom, aquaculture.

\section{INTRODUCCIÓN}

El concepto de "anillo microbiano" introducido por Azam et al (1983) cambió notablemente el rol que tienen los microorganismos en los ecosistemas acuáticos. Este concepto plantea la importancia de la interacción bacteria-microalga como componentes básicos del ecosistema, proponiendo que las bacterias no solo son recicladoras de la materia orgánica, sino que además tienen la capacidad de absorber nutrientes desde el océano y hacer circular estas fuentes de carbono mediante diversas interacciones ecológicas con los otros componentes del plancton.
Dentro de estos componentes, uno de los organismos con los cuales las bacterias interactúan directamente son las microalgas. Diversas investigaciones a nivel de laboratorio y en terreno han demostrado fenómenos de estímulo e inhibición de crecimiento en microalgas y/o bacterias (Sieburth 1959, 1971, Kogure et al. 1979). Las bacterias pueden incrementar el crecimiento microalgal (Berland et al. 1970) mediante la producción de algunas vitaminas y factores de crecimiento (Haines \& Guillard 1974). Por otro lado, se ha demostrado que las substancias orgánicas derivadas del fitoplancton en ecosistemas naturales son utilizadas por las bacterias como substrato de crecimiento 
(Ohara et al. 1993). De este modo, las bacterias transforman substratos complejos en formas más fáciles de utilizar por otros organismos heterotróficos, dando una continuidad al flujo del carbono en el ambiente acuático (Malone \& Ducklow 1990, Sundh 1992).

Estudios recientes empleando modernas técnicas moleculares demostraron que el desarrollo de un "bloom" de diatomeas depende de la dinámica de la comunidad bacteriana y las partículas asociadas a estas (Riemann et al. 2000). No obstante, algunos componentes de las comunidades bacterianas actúan también como antagonistas de algas (Safferman \& Morris 1962, Blasco 1965, Shilo 1970) e incluso en aguas costeras son capaces de lisar células microalgales, denominándose "bacterias asesinas" (Baker \& Herson 1978, Ishio et al. 1989, Sakata 1990, Imai et al. 1993, 1995, Yoshinaga et al. 1997).

Por lo tanto, las interacciones que se producen entre bacteria-fitoplancton son recíprocas y están determinadas principalmente por la utilización y producción de carbono orgánico disuelto, por células algales y su efecto en el crecimiento bacteriano (Fogg 1983, Jones \& Cannon 1986). También, se ha sugerido que la superficie de células libres podría proveer un microambiente para los procesos bacterianos como la fijación de nitrógeno, los cuales no podrían ocurrir en la columna de agua (Paerl \& Pinckney 1996). Además, diversos antecedentes evidencian la posibilidad que en ecosistemas acuáticos las interacciones bacteria-fitoplancton sean específicas (especie-especie), provocando un efecto positivo (simbiosis) o negativo (antagonismos), dependiendo de las condiciones del ecosistema

El presente estudio tiene como objetivo revisar el conocimiento generado sobre el rol que juegan las bacterias y fitoplancton en ambientes marinos y dulceacuícolas, definiendo las posibles aplicaciones que pueden tener estos microorganismos en el manejo de las aguas costeras y sistemas acuícola.

\section{INTERACCIONES POSITIVAS}

En general se acepta que uno de los factores más importantes que afecta el crecimiento de los componente bacterianos en el ecosistema acuático es la producción primaria (Bell \& Mitchell 1972, Bird \& Kalff 1984), debido a que los productos extracelulares del fitoplancton estimulan la proliferación de bacterias (Hellebust 1974, Riquelme \& Ishida 1988, Servais \& Billen 1993). Así por ejemplo, Cole et al. (1988) analizaron setenta estudios sobre la relación existente entre la productividad primaria y diversos parámetros del bacterioplancton en sistemas marinos y dulceacuícola, detectando una correlación positiva entre la abundancia de bacterias y fitoplancton. Estudios más recientes reafirman la relación existente entre ambos componentes, señalando además, que la interrelación del bacterioplancton es dependiente de variables estacionales (primavera-verano), parámetros físico-químicos y biológicos (Kormas et al. 1998, Ducklow 1999). Estos factores podrían actuar en forma separada o bien interrelacionadas, dando como resultado una mayor o menor disponibilidad de carbono orgánico en ecosistemas acuáticos. Por lo cual, las bacterias son los principales responsables de la mineralización de carbono orgánico e intermediarios de estos en la cadena trófica (Azam et al. 1983).

De esta forma, el bacterioplancton en aguas costeras se transforma en la principal fuente de materia orgánica, así por ejemplo, el porcentaje de la producción bacteriana consumida por flagelados varía entre 16,5 a $33 \%$ (Barcina et al. 1992). Esta situación podría deberse a que el $30 \%$ del material excretado por el fitoplancton circula a través de las bacterias heterótrofas (Iturriaga \& Zsolnay 1983). A pesar que la presencia constante de bacterias asociadas al fitoplancton es considerada un fenómeno natural, Riquelme et al. (1987) han puesto en evidencia que la mayor densidad de bacterioplancton ocurre solo después de la máxima producción de fitoplancton, sugiriendo que este aumento bacteriano se produce por la utilización del fitoplancton muerto y detritus. Guixa-Boixereu et al. (1999) han demostrado en experiencias realizadas "in vitro" que la máxima abundancia de bacterias $\left(3 \times 10^{7}\right.$ bacteria $\left.\mathrm{mL}^{-1}\right)$, se obtiene después de la máxima producción de clorofila a (80 $\left.\mathrm{mg} \mathrm{L}^{-1}\right)$. Estudios realizados en la década de los ochenta señalan la existencia de una fuerte correlación estadística entre ambos parámetros (Aizaki et al. 1981, Bird \& Kalff 1984). Debido a lo anterior, es importante considerar al momento de estudiar las interrelaciones microbianas en los ecosistemas acuáticos que los componentes del fitoplancton influencian la bacterioflora asociada, mientras que la densidad bacteriana se correlaciona con la abundancia del fitoplancton.

\section{INTERACCIONES NEGATIVAS}

Este tipo de interacciones pueden separarse de acuerdo al comportamiento de las bacterias y 
fitoplancton en el ecosistema acuático en dos tipos (Tabla 1).

\section{(a) Antagonismo bacteriano}

El fitoplancton pequeño $(1<\mathrm{mm})$ se encuentra constituido por cianobacteria y algas eucarióticas, las cuales se extienden por todos los océanos. En el medio natural este fitoplancton no se encuentra solo, sino que interactuando con otros microorganismos como zooplancton, bacterias y virus (Suttle et al. 1990). Generalmente son estos últimos microorganismos los principales responsables del decaimiento de un "bloom" fitoplanctónico en aguas costeras (Honjo 1993, Suttle 1993, 1994, Bratbak et al. 1995, Turutani et al. 2000). Bratbak et al. (1990) al analizar las fluctuaciones de la abun- dancia de partículas virales durante un "bloom" de fitoplancton, detectaron un rápido incremento de la abundancia de partículas virales después de la máxima abundancia de bacterias. Ellos sugieren que una proporción de la población bacteriana ha sido lisada por las partículas virales. Este fenómeno ha sido confirmado en condiciones de laboratorio por Suttle et al. (1990) y Suttle (1992), quienes al adicionar un virus nativo en cultivos de fitoplancton observaron una significativa reducción de la biomasa fitoplanctónica, siendo atribuida la lisis microalgal a la alta concentración de partículas virales en el agua de mar $\left(10^{6}-10^{9}\right.$ partículas $\left.\mathrm{x} \mathrm{mL} \mathrm{m}^{-1}\right)$.

En el caso de los componentes bacterianos, esta capacidad para provocar la inhibición y lisis de células algales ha sido extensamente estudiada en aguas costeras, determinándose que

TABLA 1

Tipos de interacciones bacteria-microalga descritas en la literatura

Types of bacteria-microalgae interaction described in the literature

\begin{tabular}{|c|c|c|c|}
\hline Microorganismo & Actividad & Especie afectada & Referencia \\
\hline \multicolumn{4}{|l|}{ Microalgas } \\
\hline Asterionella gracilis & Promotora & Pseudomonas sp., Vibrio sp. & Riquelme \& Ishida (1988) \\
\hline Skeletonema costatum & Promotora & $\begin{array}{l}\text { Vibrio sp., Flavobacterium sp., Aeromonas sp., } \\
\text { Plesiomonas sp. }\end{array}$ & Rico-Mora \& Voltolina (1995) \\
\hline Chattonella marina & Antibacteriana & Pseudomonas & Riquelme \& Ishida (1988) \\
\hline Skeletonema costatum & Antibacteriana & Vibrio sp., Listonella anguillarum, Vibrio fisheri & $\begin{array}{l}\text { Simidu et al. (1977), Cooper et al. (1983), } \\
\text { Naviner et al. (1999) }\end{array}$ \\
\hline Tetraselmis suecica & Antibacteriana & $\begin{array}{l}\text { Listonella anguillarum, Vibrio alginolyticus, } \\
\text { Vibrio salmonicida, Vibrio vulnificus, Vibrio sp. }\end{array}$ & $\begin{array}{l}\text { Viso et al. (1987), Kellan \& Walker (1989), } \\
\text { Austin \& Day (1990), Olsen et al. (2000) }\end{array}$ \\
\hline Chlorella sp. & Antibacteriana & Vibrio harveyi & Tendencia \& de la Peña (2003) \\
\hline \multicolumn{4}{|l|}{ Bacterias } \\
\hline Flavobacterium NAST & Promotora & Asterionella gracilis & Riquelme et al. (1988) \\
\hline $\begin{array}{l}\text { Vibrio sp. C33, } \\
\text { Pseudomonas sp. } 11 \text {, } \\
\text { Arthrobacter } \text { sp. } 77\end{array}$ & Promotora & Isochrysis galbana & Avendaño \& Riquelme (1999) \\
\hline $\begin{array}{l}\text { Pseudomonas sp., } \\
\text { Xanthomona sp., } \\
\text { Flavobacterium sp. }\end{array}$ & Promotora & Oscillatoria sp. & Delucca \& Mc Cracken (1977) \\
\hline $\begin{array}{l}\text { Pseudoalteromonas } \\
\text { peptidysin }\end{array}$ & Algicida & $\begin{array}{l}\text { Gymnodinium catenarum, Chattonella marina, } \\
\text { Heterosigma akashiwo }\end{array}$ & Lovejoy et al. (1998) \\
\hline Saprospira sp. SS-K1 & Algicida & Isochrysis sp., Chaetoceros sp. & Sakata (1990) \\
\hline Cytophaga sp. & Algicida & Chattonella antiqua & Imai et al. (1991) \\
\hline Flavobacterium sp. $5 \mathrm{~N}-3$ & Algicida & $\begin{array}{l}\text { Gymnodinium nagasakiense, Chattonella } \\
\text { antiqua, Chattonella marina }\end{array}$ & Fukami et al. (1992) \\
\hline
\end{tabular}


las bacterias y sus productos extracelulares son un factor clave para el rápido decaimiento de floraciones fitoplanctónicas (Ishio et al. 1989, Sakata 1990, Imai et al. 1991, Fukami et al. 1992, Yoshinaga et al. 1995a). Observaciones mediante microscopia electrónica de Skeletonema costatum durante el colapso de un "bloom" fitoplanctónico, permitieron observar una rápida colonización bacteriana de las células microalgales, las cuales provocan una rápida senescencia y/o muerte de la diatomea (Bratbak et al. 1990).

Estas bacterias antagónicas son capaces de actuar sobre un amplio rango de los componentes del plancton, incluyendo diatomeas, dinoflagelados y algunas bacterias de los géneros $\mathrm{Vi}$ brio, Acinetobacter y Flavobacterium (Fukami et al. 1992, Yoshinaga et al 1997). Estudios desarrollados por investigadores japoneses han permitido elucidar que las interacciones bacteria-microalga son altamente específicas, al respecto Fukami et al. (1992), detectaron que una bacteria del género Flavobacterium aislada desde el agua de mar, inhibe específicamente el crecimiento de una microalga. Esta cepa se incorporó en cultivos del dinoflagelado Gymnodinium nagasakiense y las diatomeas Chattonella antiqua, Heterosigna akashiwo y S. costatum detectándose efectos deletéreos solo en G. nagasakiense, el cual fue atribuido a los productos extracelulares liberados por la bacteria. Yoshinaga et al. (1997) muestran similares resultados con la cepa Flavobacterium sp. C49, la cual inhibe $H$. akashiwo sin afectar otros dinoflagelados y diatomeas estudiadas. Un hallazgo interesante fue el dado a conocer por Sakata (1990), quien aisló una cepa identificada como Saprospira sp. SS-K1 capaz de producir la lisis de Isochrysis sp. y Chaetoceros calcitrans. Estas microalgas constituyen la principal fuente de alimento en diversos cultivos de moluscos bivalvos (Bourne et al. 1989, Brown et al. 1997).

Al parecer, esta actividad algicida estaría finalmente determinada por la concentración bacteriana (Fukami et al. 1991, Kim et al. 1998). Fukami et al. (1992) mostraron en experiencia "in vitro" realizada con la cepa $5 \mathrm{~N}-3$ que concentraciones mayores a $10^{6}$ células $\mathrm{x} \mathrm{mL} \mathrm{mL}^{-1}$ causan efectos deletéreos en el crecimiento de $G$. nagasakiense. Otro estudio realizado por Lovejoy et al. (1998), detectaron que la concentración mínima de una cepa del género Pseudoalteromonas para provocar la lisis de Gymnodinium catenarum, se encuentra entre $10^{3}$ a $10^{4}$ células $\mathrm{x}$ $\mathrm{mL}^{-1}$. Lo anteriormente expuesto permite sugerir que diversas bacterias podrían actuar como algicidas o inhibidores del crecimiento microalgal, mediante la excreción de productos extracelula- res o contacto directo con las bacterias-microalga. De esta forma, las bacterias serían uno de los agentes controladores de la sucesión y estructuras de las comunidades fitoplantónicas en los ecosistemas marinos.

\section{(b) Antagonismo microalgal}

Actividad antagónica también ha sido descrita en el caso inverso, es decir efectos antibacterianos producidos por algunas clases de microalgas y principalmente diatomeas, las cuales son el mayor constituyente del fitoplancton (Reichel \& Borowitska 1984, Viso et al. 1987, Pesando 1990). La presencia de estas microalgas afectan la composición de las comunidades bacterianas principalmente por medio de la producción de substancias antibacterianas, así por ejemplo, Tetraselmis ha sido extensamente descrita como una microalga con capacidad inhibitoria de bacterias, fenómeno considerado como natural (Duff et al. 1966, Kellam \& Walker 1989, Austin \& Day 1990, Austin et al. 1992). Similares propiedades antibacterianas han sido descritas en cultivos microalgales de $S$. costatum (Kogure et al. 1979, Cooper et al. 1983, Naviner et al. 1999) y diversas especies del género Chaetoceros (Gauthier et al. 1978, Viso et al. 1987). En el caso particular de $S$. costatum se ha determinado que la actividad antibacteriana es provocada por la combinación de algunos ácidos grasos (Naviner et al. 1999). Además, Kellam et al. (1988) señalan que ácidos grasos con más de 10 átomos de carbono en su estructura inducen a la lisis del protoplasto bacteriano.

Sin embargo, la mayoría de las experiencias han sido efectuadas con cultivos microalgales no axénicos, por lo cual la capacidad inhibitoria de las microalgas sería provocada por la bacterioflora asociada a las mismas. Por ejemplo, Rico-Mora \& Voltolina (1995), reportan que la actividad antibiótica y bacteriostática de $S$. costatum sobre bacterias presentes en el cultivo, es provocado por otras dos bacterias asociadas a la microalga, siendo identificadas como Aeromonas sp. y Flavobacterium sp. Probablemente, interacciones de este tipo podrían constituirse en una estrategia para mantener un bajo crecimiento bacteriano en los cultivos microalgales. Posteriormente, los mismos autores corroboran las propiedades antibacterianas de una de las bacterias contra el patógeno Vibrio alginolyticus, señalando que la eliminación de este se debe a un mecanismo de exclusión competitiva (Rico-Mora \& Voltolina 1998).

Según Fredrickson \& Stephanopoulos (1981) las interrelaciones de este tipo son originadas al comienzo por la competencia por nu- 
trientes y derivan luego en antagonismo e interferencia. De esta forma, los microorganismos evolucionan desarrollando mecanismos de producción de sustancias con actividad antibiótica, manteniendo así la dinámica y estructura de las poblaciones bacterianas en los microambientes algales. Estudios recientes han demostrado que la relación de mutualismo entre fitoplancton y bacterias, mediante la producción y consumo de carbono orgánico extracelular, se rompe en condiciones limitantes de nutrientes (Aota \& Nakajima 2001). Así por ejemplo, cuando el fósforo es limitante, las bacterias compiten con el fitoplancton provocando un incremento de la tasa de mortalidad del fitoplancton. Por lo tanto, el grado de influencia de la comunidad bacteriana sobre la dinámica del fitoplancton depende del tipo de nutriente limitante (Brussaard \& Riegman 1998).

\section{APLICACIONES DE LAS INTERACCIONES BACTERIA-MICROALGA}

Las interacciones de antagonismo descritas anteriormente nos permiten vislumbrar un importante potencial de bacterias y microalgas marinas en el biocontrol de "bloom" fitoplantónicos no deseados y epizootias en ambientes naturales y/o sistemas de cultivos de origen bacteriano.

\section{Control de "blooms" fitoplanctónicos}

En el caso de ambientes marinos la relevancia ecológica de la actividad algicida está dada por el control de la sucesión fitoplanctónica, como ha sido demostrado por numerosos trabajos de campo. Esto supone que si bien algunas bacterias promueven y estimulan selectivamente la formación de "bloom" fitoplanctónicos (Furuki \& Kobayashi 1991), existen otras que tienen efecto algicida sobre diferentes estados del fitoplancton, controlando y provocando el término y descomposición de los "blooms" (Fukami et al. 1991, 1996).

La gran mayoría de los estudios de control de "blooms" fitoplanctónicos han sido realizados en ecosistemas acuáticos de las costas japonesas, debido a la frecuencia de "bloom" fitoplantónicos en ese país. Fukami et al. (1996), al estudiar el efecto de los agregados microbianos durante un "bloom" fitoplanctónico en Uranouchi Inlet (Kochi), observaron la reducción específica de Gymnodinium mikimotoi y la sucesión de un "bloom" secundario dominado por S. costatum. Otro estudio llevado a cabo durante el decaimiento de un "bloom" de G. mikimotoi en Tanabe Bay, Wakayama permitió a Yos- hinaga et al. (1995b) el aislamiento de la bacteria causante de la caída del "bloom", siendo codificada como Gm-GIB. Basados en estos estudios Kim et al. (1998) examinaron el efecto que tienen las bacterias en el decaimiento de $H$. akashiwo en aguas costeras de Hiroshima Bay entre 1994 a 1995. Ellos reportaron la existencia de numerosas bacterias "asesinas" de la microalga. Además, muestreos realizados "in situ" permitieron aislar dos cepas bacterianas (MC10 y GY14), las cuales al ser utilizadas en experiencias "in vitro" colocaron en evidencia a los pocos días de cultivo mixto con $H$. akashiwo una alta actividad algicida. En cambio, al evaluar la acción de estas bacterias sobre el crecimiento de $C h$. antiqua, no se detectaron efectos deletéreos. Resultados similares fueron obtenidos en estudios realizados por Yoshinaga et al. (1997), quienes utilizaron a la bacteria Flavobacterium sp. (cepa C49) para inhibir selectivamente a $H$. akashiwo, sin afectar a otras diatomeas estudiadas.

Lovejoy et al. (1998) señalan que las bacterias inhibitorias del crecimiento algal actúan mediante dos mecanismos, directo e indirecto. Un ejemplo del primer mecanismo es la rápida y efectiva lisis provocada por Cytophaga sp. (cepa J18/M01) sobre cultivos algales de Chattonella y Heterosigma después de $2 \mathrm{~h}$ de inoculación, efecto que no fue detectado cuando se adicionaron los productos extracelulares de la bacteria (Imai et al. 1993). Por su parte, los ataques indirectos corresponden a la inhibición de algas mediante la producción y liberación de exudados extracelulares con propiedades antagonistas. Lovejoy et al. (1998), al evaluar el efecto de dos cepas de Pseudoalteromonas sp. aisladas desde Huon Estuary, Tasmania (Australia) sobre el crecimiento de $G$. catenarum, Ch. marina y $H$. akashiwo, detectaron que la presencia de estas bacterias causan efectos adversos en los tres dinoflagelados estudiados. A pesar que estos autores no identificaron el mecanismo causante de la inhibición, sugieren que podría estar asociado a substancias de alto peso molecular, similar a lo descrito en $P$. rubra y $P$. luteoviolocea (Baumann et al. 1984). Estudios recientes han reportado que otra bacteria del género Pseudoalteromonas sp. (cepa A28) provoca la lisis algal, actuando a nivel de la síntesis de las proteínas ${ }^{1}$. En general, Pseudoalteromonas, Alteromonas y

\footnotetext{
1 KATO J, T IKEDA, A KURODA, TAKIGUCHI \& H OHTAKE (1999) Influence of Pseudoalteromonas sp. A28 extracellular products on the synthesis of proteases exhibiting lytic activity toward marine algae. Abstracts of the 99th General Meeting of American Society for Microbiology, Washington, District of Columbia, USA: Abstract 104.
} 
Flavobacterium han sido constantemente reconocidas por agrupar especies que viven en asociación a invertebrados marinos y algas, las cuales mediante compuestos extracelulares, inhiben y controlan la presencia de muchos de sus organismos asociados (Gauthier \& Flatau 1976, Nair \& Simidu 1987, Holmström \& Kjelleberg 1999, Egan et al. 2000, 2001, Jayanth et al. 2001). Sin embargo, los estudios para determinar los mecanismos de inhibición son escasos, así como las moléculas que participan en estos son raramente purificadas.

La integración de los conocimientos anteriormente descritos permitió en la década de los 90 a la Agencia de Pesquerías del Gobierno Japonés, iniciar estudios para prevenir y controlar la presencia de mareas rojas mediante la utilización de bacterias "asesinas". Sin embargo, los resultados fueron impracticables debido a diversos factores. Así por ejemplo, en el caso del dinoflagelado $G$. nagasakiense las concentraciones letales de la bacteria $5 \mathrm{~N}-3$ son demasiado altas para inocular "in situ", lográndose concentraciones de $10^{7}$ células $\mathrm{x} \mathrm{mL} \mathrm{mL}^{-1}$ solo cuando la bacteria se encuentra asociada a $S$. costatum, H. akashiwo y Ch. antiqua. Por esta razón, Fukami et al. (1992) sugieren utilizar carbono orgánico desde fitoplancton natural para incrementar la densidad de la cepa $5 \mathrm{~N}-3$.

Sin embargo, el impacto de las microalgas tóxicas no se limita a ambientes abiertos sino que se ha convertido en un serio problema en cultivos cerrados de especies acuícola, principalmente moluscos y peces (Shumway 1990, Noga 1998). En el caso particular de moluscos bivalvos el impacto del fitoplancton es causado por la filtración de estos y la acumulación de sus toxinas, siendo considerado un fenómeno común en organismos filtradores (Shumway 1990). Por otro lado, la detección en el agua de cultivo de peces de microalgas tóxicas pertenecientes a los géneros Alexandrium, Chattonella, Heterosigma y Chaetoceros han sido señaladas como las causantes de devastadores efectos sobre la producción de la industria piscícola (Noga et al. 1993, Landsberg et al. 1995, Noga 1998). Por ejemplo, diatomeas del género Chaetoceros han sido asociadas con mortalidades en el cultivo de salmones (Rensel 1993). Si bien la mortalidad de los peces en muchos de los casos es atribuida a las algas tóxicas se desconoce el mecanismo de acción de estas, observándose solo síntomas de desorientación e hiperactividad de los peces cultivados. Aunque, estudios realizados por Kent (1992) señalan que la mortalidad de los peces se encuentra asociada a la obstrucción mecánica de las branquias, provocando la hipoxia de los mismos. La presencia de estas algas toxicas en sistemas cerrados como estanques de cultivos podría facilitar la aplicación de componentes bacterianos como biocontroladores de floraciones algales no deseadas, similar al programa desarrollado por la Agencia de Pesquerías del Gobierno Japonés, constituyéndose en una alternativa para resolver este problema.

La información recopilada sugiere que es practicable la utilización de bacterias "asesinas", para controlar y manipular el desarrollo de "bloom" fitoplanctónicos perjudiciales en ambientes confinados como los sistemas acuícolas. Sin embargo, se requiere previamente estudiar las características y mecanismos de acción de las bacterias sobre los componentes del "bloom" fitoplanctónico, así como los efectos en los organismos cultivados.

\section{Control bacteriológico en sistemas acuícolas}

Las microalgas juegan un papel predominante en el desarrollo de la acuicultura, ya que constituyen el primer alimento vivo para las fases tempranas de desarrollo de casi todos los organismos cultivados, siendo altamente nutritivas y fácil de ingerir debido al tamaño que poseen (Brown et al. 1997). No obstante, en los sistemas de producción acuícola es imposible trabajar con cultivos microalgales axénicos, debido a que las células de microalgas secretan substancias que estimulan el crecimiento bacteriano (Servais \& Billen 1993, Munro et al. 1995). De esta forma el alimento utilizado en los sistemas de cultivos es mixto y está compuesto por una especie de microalga y una o varias bacterias asociadas, dependiendo de la especie de microalga cultivada.

El rol de las bacterias asociadas en sistemas a los cultivos masivos de microalgas (10-1.000 L) ha sido extensamente estudiado, ya que estos cultivos mixtos microalga-bacteria son fácilmente ingeridos y digeridos por los organismos, provocando mayores crecimientos e incrementando la sobrevivencia de los organismos cultivables. Experiencias realizadas en larvas de bivalvos han demostrado que las bacterias participan en procesos de digestión de las microalgas mediante la producción de enzimas extracelulares como proteasas y lipasas (Prieur et al. 1990). Por ejemplo, Brown et al. (1996), señalan que al alimentar larvas de ostra Saccostrea commercialis (Gould 1850) con mezclas de bacterias y algas, se provoca un incremento en la talla de la concha de $67 \%$, en comparación con larvas alimentadas solo con microalgas. Estudios en Pecten maximus (Linnaeus 1758), Mercenaria mercenaria (Linnaeus 1758), Argopecten ventricosus-circularis 
(Sowerby II, 1942) y Crassostrea gigas (Thunberg 1793) han demostrado la existencia de procesos selectivos en su alimentación, reflejándose una ingesta selectiva de microalgas (Robinson 1983, Le Pennec \& Rangel-Davalos 1985, Lora-Vilchis \& Maeda-Martínez 1997). Como ha sido planteado anteriormente las microalgas utilizadas comúnmente como alimento poseen microflora acompañante (Avendaño \& Riquelme 1999), siendo factible proponer que esta selectividad está dada también por las bacterias asociadas al cultivo microalgal (Olabi et al. 1999, Riquelme et al. 2000).

Por otro lado, varios estudios han señalado algunas propiedades nutritivas de las bacterias, siendo propuestas como un suplemento benéfico en la alimentación de moluscos bivalvos (Coutteau \& Sorgeloos 1992, Nell et al. 1994). Ejemplo de estos son los estudios de Albert \& Valiela (1995, 1996), quienes han evidenciado que los agregados microbianos son una importante fuente de nutrición para el pectínido Argopecten irradians (Lamarck 1819), similares resultados han sido señalados en cultivos de Artemia (Intriago \& Jones 1993). Brown et al. (1996), al evaluar la composición bioquímica de las bacterias presentes en el agua de cultivo de $S$. commerciali, reportan una alta composición proteica y aminoácidos esenciales similares a los encontrados en los tejidos de esta especie y $C$. gigas. Dentro de la gama de nutrientes aportados por las bacterias asociadas a microalgas, tanto de ambientes naturales como cultivos acuícola, los más importantes son los ácidos grasos polinsaturados, los cuales no han sido detectados en los aislados estudiados.

De esta forma, las microalgas pueden ser una vía de incorporación de bacterias benéficas a los sistemas de cultivo (Elston 1984), siendo capaces de aportar elementos nutricionales o producir substancias que inhiban el crecimiento de organismos (Garriques \& Arevalo 1995) e inhibir bacterias patógenas a través de mecanismos de exclusión competitiva (Austin et al. 1995) o mediante la producción de substancias bactericidas (Maeda \& Nogami 1989, Nogami \& Maeda 1992). Por ejemplo, Douillet \& Langdon (1994) han apreciado que cultivos de $C$. gigas en condiciones axénicas disminuye su tasa de crecimiento en relación a larvas expuestas a bacterias benéficas. Este fenómeno también ha sido demostrado en Argopecten purpuratus (Lamarck 1819) donde se detectó que larvas cultivadas en agua de mar filtrada a $5 \mu \mathrm{m}$ presentaron un incremento en la sobrevivencia y crecimiento, comparado con cultivos larvales en agua de mar filtrada a $0,2 \mu \mathrm{m}$ (sin bacterias) (Riquelme et al. 1997). Samain et al. (1987) sugieren que la diferencia en la sobrevivencia se debe a la retención por filtración de las partículas y agregados bacterianos, los cuales podrían ser utilizados por las larvas promoviendo el crecimiento.

En este último caso, las bacterias son denominadas "probióticas", concepto definido por Fuller (1999) como "aquel microorganismo vivo que suplementado al alimento afecta benéficamente al hospedador mejorando su balance microbiano intestinal". La utilización de estos microorganismos en la producción de animales terrestre ha sido extensamente estudiada (Conway 1989). Sin embargo, en ambientes acuícola las investigaciones han comenzado a realizarse solo en la última década, siendo enfocadas a la selección de bacterias y microalgas con propiedades benéficas que permitan ser utilizadas en cultivos puros o mixtos, permitiendo controlar y manipular biológicamente los sistemas de cultivo (Gatesoupe 1999, Olafsen 2001). La interacción entre estos microorganismos puede tener un rol benéfico a nivel de procesos digestivos (Tettelbach et al. 1994), inhibiendo el crecimiento de algunos patógenos (Austin el al. 1995, Nakamura et al. 1999) y/o interactuando en la mantención de la dinámica de la población bacteriana en sistemas de cultivos (Riquelme et al. 2001). De este modo, es factible modificar o manipular las comunidades microbianas en agua, sedimentos y organismos de cultivos como ha sido demostrado en varios estudios (Garriques \& Arévalo 1995, Araya et al. 1999, Riquelme et al. 2001, Avendano-Herrera et al. 2001, 2002a)

En general, la utilización de microorganismos ha sido evaluada por numerosos investigadores, las cuales han permitido controlar las infecciones asociadas a cultivos larvales de crustáceos, peces y moluscos (Westerdhal et al. 1991, Nogami \& Maeda 1992, Maeda 1994, Austin et al. 1995, Irianto \& Austin 2002). Lodeiros et al. (1988) describen que los monocultivos microalgales de Piramimonas virginica, Phytomonas sp., Tetraselmis chuii y Pseudoisochrysis paradoxa, presentan asociadas en su bacterioflora un $30 \%$ de cepas productoras de sustancias antibacterianas. Esta asociación permitiría mantener un bajo nivel bacteriano en sistemas de cultivos de organismos marinos, previniendo algunas enfermedades y además, brindar los requerimientos nutricionales necesarios.

Estudios realizados con extractos de Tetraselmis suecica indican que la producción de exudados microalgales inhiben el crecimiento de diversas bacterias patógenas en cultivos de peces (Austin et al. 1992). El mismo grupo de investigadores señala que la microalga Tetraselmis sp. afecta las comunidades bacterianas asociadas a alimento vivo. Skjermo \& Vadtein (1993) y Bergh et al. (1994), señalan que la 
adición de algas en estanques de cultivo de peces, altera considerablemente la composición de la bacterioflora asociada a larvas. Sin embargo, los factores que provocan el crecimiento bacteriano y controlan la composición de la bacterioflora en el agua de cultivo, depende de la especie de alga y el estado de crecimiento de la misma (Salvesen et al. 2000).

Otro ejemplo de la utilización de microalgas para controlar mortalidades larvales es el empleo de "aguas-verdes", el cual ha sido utilizado en el cultivo de camarones para prevenir enfermedades causadas bacterias luminosas como Vibrio harveyi (Corre et al. 2000). Los resultados de las experiencias sugieren que agua de cultivo con la incorporación de Chlorella son efectiva contra $V$. harveyi, siendo eliminado en un periodo de 3 días postinoculación (Tendencia \& de la Peña 2003).

En cultivos de Artemia franciscana, organismo utilizado como alimento para peces en acuicultura, ha sido demostrado que la adición de $T e$ traselmis sp. durante dos días reduce y modifica la carga bacteriana asociada al crustáceo (Olsen et al. 2000). Después, al evaluar este alimento en larvas de Hippoglossus hippoglossus (Linnaeus 1758), se observó la transferencia y establecimiento de los componentes bacterianos del alga en las larvas de peces. Esta experiencia demostró que la incorporación de microalgas afecta el comportamiento de la larva de $H$. hippoglossus (Naas et al. 1992). Experimentos realizados en nuestro laboratorio, con cultivos axénicos de la microalga Isochrysis galbana permitieron el establecimiento de bacterias benéficas, constituyendo cultivos mixtos microalga-bacteria (Avendaño \& Riquelme 1999). Este cultivo fue utilizado como vector para la introducción de bacterias benéficas en larvas y adultos de A. purpuratus. Los resultados demostraron una significativa ingesta e incorporación de las cepas benéficas Vibrio C33 y Pseudomonas 11 , modificando la bacterioflora nativa y estableciendo como la flora residente la Pseudomonas $11(41,8 \%)$ (Avendaño-Herrera et al. 2001). La colonización del agente bacteriano en el tracto digestivo de los organismos de cultivos en forma dominante, favorecería la sanitización natural del organismo y mejoraría la resistencia inherente a la invasión microbiana (Lemos et al. 1985, Nogami \& Maeda 1992, Munro \& Birkbeck $1993^{2}$, Araya et al. 1999).

\footnotetext{
${ }^{2}$ MUNRO PD \& TH BIRKBECK (1993) Influence of rate of bacterial colonization of the gut of turbot larvae on larval survival. En: Reinertsen H, L Dahle, L Jørgensen \& K Tvinnereim (eds) Proceeding of the First International Conference of Fish Farming Technology: 85-92. AA Balkema, Rotterdam, The Netherlands.
}

Los ensayos realizados en A. purpuratus han servido de base, para el diseño de un protocolo para la producción masiva de cultivos mixtos en "hatchery" comercial y de esta forma hacer factible cultivar moluscos sin la utilización continua de antibióticos (Riquelme et al. 2001, Avendaño-Herrera et al. 2002b). En la actualidad las investigaciones están enfocadas en incorporar estos microorganismos benéficos en la dieta de peces y moluscos en forma de pellet, microencapsulados y/o inactivados con formol, siendo demostrado su efecto benéfico en la respuesta inmune de los organismos enfrentados al patógeno (Irianto \& Austin 2002, 2003).

Los antecedentes proporcionados en esta revisión permiten sugerir que bacterias $\mathrm{y} / \mathrm{o} \mathrm{mi-}$ croalgas, constituyen una alternativa para el control de proliferaciones de bacterias y fitoplancton causantes de efectos dañinos en ambientes naturales y sistemas cerrados de cultivo. Además, el conocimiento de interacciones específicas entre bacteria-microalga permite la optimización de sistemas productivos para la acuicultura disminuyendo los costos, facilitando el manejo, reduciendo el uso de antibióticos y otros químicos que causan deterioro ambiental. Sin embargo, el mecanismo de estas interacciones son pobremente entendidos. Futuras investigaciones debieran ser dirigidas a entender el modo de acción de las interacciones bacteria-microalga a nivel molecular.

\section{AGRADECIMIENTOS}

Los autores agradecen la revisión y comentarios del Profesor Ismael Kong de la Universidad de Antofagasta y el financiamiento al Proyecto FONDEF DOOI1168.

\section{LITERATURA CITADA}

AIZAKI M, A OTSUKI, T FUKUSHIMA, M HOSOMI \& K MURAOKA (1981) Application of Carlson's tropic state index to Japanese lakes and relationships between the index and other parameters. Verhandlungen de Internationalen Vereinigung Limnology 21: 675-681.

ALBER M \& I VALIELA (1996) Utilization of microbial organic aggregates by bay scallops Argopecten irradians (Lamarck). Journal of Experimental Marine Biology and Ecology 195: 71- 89.

ALBER M \& I VALIELA (1995) Organic aggregates in detrital food webs: incorporation by bay scallops Argopecten irradians. Marine Ecology Progress Series 121: 117-124.

AOTA Y \& H NAKAJIMA (2001) Mutualistic relationships between phytoplankton and bacteria caused by excretion from phytoplankton. Ecological Research 16: 289-299. 
ARAYA RA, MA JORQUERA \& CE RIQUELME (1999) Asociación de bacterias al ciclo de vida de Argopecten purpuratus. Revista Chilena de Historia Natural 72: 261-271.

AUSTIN B \& JG DAY (1990) Inhibition of prawn pathogenic Vibrio spp. by a commercial spray-dried preparation of Tetraselmis suecica. Aquaculture 90: 389-392.

AUSTIN B, E BAUDET \& M STOBIE (1992) Inhibition of bacterial fish pathogens by Tetraselmis suecica. Journal of Fish Diseases 15: 55-61.

AUSTIN B, L STUCKEY, P ROBERSTON, I EFFENDI \& D GRIFFITH (1995) A probiotic strain of Vibrio alginolyticus effective in reducing disease caused by Aeromonas salmonicida, Vibrio anguillarum and Vibrio ordalli. Journal of Fish Diseases 18: 93 - 96.

AVENDAÑO R \& C RIQUELME (1999) Establishment of mixed-culture probiotics and microalgae as food for bivalve larvae. Aquaculture Research 30: 893-900.

AVENDAÑO-HERRERA R, M DEKOVIC \& C RIQUELME (2001) Establecimiento de bacterias benéficas en el tracto digestivo y gónada de adultos de Argopecten purpuratus (Lamarck 1819) en cultivo masivo. Revista de Biología Marina y Oceanografía (Chile) 36: 31-41.

AVENDAÑO-HERRERA R, C RIQUELME \& F SILVA (2002a) Utilización de biopelículas bacterianas en el asentamiento de larvas de Argopecten purpuratus (Lamarck 1819) en un hatchery comercial. Revista de Biología Marina y Oceanografía (Chile) 37: 35-41.

AVENDAÑO-HERRERA R, M JORQUERA, A ROJAS, F SILVA \& CE RIQUELME (2002b) Rol de microorganismos en el cultivo de Argopecten purpuratus. Acta Microbiológica (Chile) 8: 1-10.

AZAM F, T FENCHEL, JG FIELD, JS GRAY, LA MEYER-REIL \& F THINGSTAD (1983) The ecological role of water-column microbes in the sea. Marine Ecology Progress Series 10: 257-263.

BAKER KH \& DS HERSON (1978) Interaction between the diatom Thallasiosira pseudonana and an associated pseudomonad in a mariculture system. Applied and Environmental Microbiology 35: 791-796.

BARCINA I, B AYO, M UNANUE, L EGEA \& J IRIBERRI (1992) Comparison of rates of flagellate bacterivory and bacterial production in marine coastal system. Applied and Environmental Microbiology 58: 3850-3856.

BAUMANN JP, MJ GAUTHIER \& L BAUMANN (1984) Genus Alteromonas Baumann, Baumann, Mandel and Ellen 1972. En: Kreig NR \& JG Holt (eds) Bergey's manual of systematic bacteriology: 343-352. Williams \& Wilkins, Baltimore, Maryland, USA

BELL WH \& R MITCHELL (1972) Chemostatic and growth responses of marine bacteria to algal extracellular product. Biological Bulletin, Marine Biological Laboratory 143: 265-277.

BERGH O, K NAAS \& T HARBOE (1994) Shift in intestinal microflora of Atlantic halibut (Hippoglossus hippoglossus L) during first feeding. Canadian Journal of Fisheries and Aquatic Science 51: 1899-1903.

BERLAND BR, DJ BONIN \& SY MAESTRINI (1970) Study of bacteria associated with marine algae in culture. III. Organic substrates supporting growth. Marine Biology 5: 68-76.

BIRD DF \& J KALFF (1984) Empirical relationships between bacterial abundance and chlorophyll concentration in fresh and marine water. Canadian Journal of Fisheries and Aquatic Science 41: 1015-1023.

BLASCO RJ (1965) Nature and role of bacterial contaminants in mass cultures of thermophilic Chlorella pyrenoidosa. Applied Microbiology 13: 473-477.
BOURNE N, CA HODGSON \& INC WHYTE (1989) A manual for scallop culture in British Columbia. Canadian Technology Report Fish Aquatic Science 19: 64-215.

BRATBAK G, M HELDAL, S NORLAND \& TF THINGSTAD (1990) Viruses as partners in spring bloom microbial trophodynamics. Applied and Environmental Microbiology 56: 1400-1405.

BRATBAK G, M LEVASSEUR, S MICHAUD, G CANTIN, E FERNANDEZ, BR HEIMDAL \& M HELDAL (1995) Viral activity in relation to Emiliania huxleyi blooms: a mechanism of DMSP release? Marine Ecology Progress Series 128: 133-142.

BROWN MR, SW JEFFREY, JK VOLKMAN \& GA DUNSTAN (1997) Nutritional properties of microalgae for mariculture. Aquaculture 151: 315-331

BROWN MR, SM BARRETT, JK VOLKMAN, SP NEARHOS, JA NELL \& GL ALLAN (1996) Biochemical composition of new yeasts and bacteria evaluated as food for bivalve aquaculture. Aquaculture 143: 341-360.

BRUSSAARD CPD \& R RIEGMAN (1998) Influence of bacteria on phytoplankton cell mortality with phosphorus or nitrogen as the algal-growth-limiting nutrient. Aquatic Microbial Ecology 14: 271-280.

COLE J, M PACE \& S FINDLAY (1988) Bacterial production in fresh and saltwater ecosystems: a cross system overview. Marine Ecology Progress Series 43: 1-10.

CONWAY PL (1989) Lactobacilli: fact and fiction. En: Grubb R, T Midvet \& E Norin (eds) The regulatory and protective role of the normal microflora: 263281. Macmillan Press, London, England.

COOPER S, A BATTAT, P MAROT \& M SYLVESTER (1983) Production of antibacterial activities by two bacillariophyceae growth in dialysis culture. Canadian Journal of Microbiology 29: 338-341.

CORRE VL, R JANEO, CM CAIPANG \& AT CALPE (2000) Use of probiotics and reservoirs with "green water". Aquaculture Asia V 2: 34-38.

COUTTEAU P \& P SORGELOOS (1992) The use of algal substitutes and the requirement for live algae in hatchery and nursery of bivalve mollusk: an international survey. Journal of Shellfish Research 11: 467-476.

DELUCCA R \& M McCRAKEN (1977) Observations on interactions between naturally collected bacteria and several species of algae. Hydrobiologia 55: 71-75.

DOUILLET PA \& CJ LANGDON (1994) Use of probiotic for the culture of larvae of the Pacific oyster (Crassostrea gigas Thunberg). Aquaculture 119: 25-40.

DUCKLOW HW (1999) The bacterial component of the oceanic euphotic zone. FEMS Microbiology Ecology 30: 1-10.

DUFF DCB, DL BRUCE \& N ANITA (1966) The antibacterial activity of marine planktonic algae. Canadian Journal of Microbiology 12: 877-884.

EGAN S, S JAMES, C HOLMSTRÖM \& S KJELLEBERG (2001) Inhibition of algal spore germination by the marine bacterium Pseudoalteromonas tunicata. FEMS Microbiology Ecology 35: 67-73.

EGAN S, T THOMAS, C HOLMSTRÖM \& S KJELLEBERG (2000) Phylogenetic relationship and antifouling activity of bacterial epiphytes from the marine alga Ulva lactuca. Environmental Microbiology 2: 343-347.

ELSTON RA (1984) Prevention and management of infectious diseases in intensive mollusc husbandry. Journal of the World Mariculture Society $15: 284-300$.

FOGG GE (1983) The ecological significance of extracellular products of phytoplankton photosynthesis. Botanica Marina 26: 3-14. 
FREDRICKSON AG \& G STEPHANOPOULOS (1981) Microbial competition. Science 213: 972-979.

FUKAMI K, K SAKAGUCHI, M KANOU \& T NISHIJIMA (1996) Effect of bacterial assemblages on the succession of blooming phytoplankton from Skeletonema costatum to Heterosigma akashiwo. En: Yasumota T, Y Oshima \& Y Fukuyo (eds) Harmful and toxic algal blooms: 335-338. Intergovernmental Oceanographic Commission of UNESCO, Paris, France.

FUKAMI K, A YUZAWA, T NISHIJIMA \& Y HATA (1992) Isolation and properties of a bacterium inhibiting the growth of Gymnodinium nagasakiense. Nippon Suisan Gakkaishi 58: 1073-1077.

FUKAMI K, T NISHIJIMA, H MURATA, S DOI \& Y HATA (1991) Distribution of bacteria influential on the development and the decay of Gymnodinium nagasakiense red tide and their effects on algal growth. Nippon Suisan Gakkaishi 57: 2321-2326.

FULLER R (1999) Probiotic for farm animals. En: Tannock GW (ed) Probiotics: a critical review: 15-22. Horizon Scientific Press, Wymondham, England.

FURUKI M \& M KOBAYASHI (1991) Interaction between Chattonella and bacteria and prevention of this red tide-EMECS '90. Marine Pollution Bulletin 23: 189-193.

GARRIQUES D \& G AREVALO (1995) An evaluation of the production and use of a live bacterial isolate to manipulate the microbial flora in the commercial production of Penaeus vannamei post-larvae in Ecuador. En: Browdy CL \& JS Hopkins (eds) Swimming through troubled water: 53-59. World Aquaculture Society, Baton Rouge, Lousiana, USA.

GATESOUPE FJ (1999) Review: the use of probiotics in aquaculture. Aquaculture 180: 147-165.

GAUTHIER MJ \& GN FLATAU (1976) Antibacterial activity of marine violet-pigmented Alteromonas with special reference to the production of brominated compounds. Canadian Journal of Microbiology 22: 1612-1619.

GAUTHIER MJ, P BERNARD \& M AUBERT (1978) Production d' un antibiotique lipidique photo-sensible par la diatomée marine Chaetoceros lauderi (RALFS). Annual Microbiology 129: 63-70.

GUIXA-BOIXEREU N, K LYSNES \& C PEDRÓS-ALIÓ (1999) Viral lysis and bacterivory during a phytoplankton bloom in a coastal water microcosm. Applied and Environmental Microbiology 65: 1949-1958.

HAINES KC \& RL GUILLARD (1974) Growth of vitamin $\mathrm{B}_{12}$ requiring marine diatoms in mixed laboratory cultures with vitamin $\mathrm{B}_{12}$ producing marine bacteria. Journal of Phycology 10: 245-252.

HELLEBUST JA (1974) Extracelular products. En: Steward WDP (ed) Algal physiology and biochemistry: 838-863. Blackwell Scientific, London, England.

HOLMSTRÖM C \& S KJELLEBERG (1999) Marine Pseudoalteromonas species are associated with higher organisms and produce biologically active extracellular agents. FEMS Microbiology Ecology 30: 285-293.

HONJO T (1993) Overview on bloom dynamic and physiological ecology of Heterosigma akashiwo. En: Smayda TJ \& Y Shimidu (eds) Toxic phytoplankton blooms in the sea. Elsevier, Amsterdam, The Netherlands.

IMAI I, Y ISHIDA \& Y HATA (1993) Killing of marine phytoplankton by a gliding bacterium Cytophaga sp., isolated from the coastal sea of Japan. Marine Biology 116: 527-532.
IMAI I, Y ISHIDA, S SAWAYAMA \& Y HATA (1991) Isolation of marine gliding bacterium that kills Chattonella antiqua (Raphidophyceae). Nippon Suisan Gakkaishi 57: 1409.

IMAI I, Y ISHIDA, K SAKAGUCHI \& Y HATA (1995) Algicidal marine bacteria isolated from northern Hiroshima Bay, Japan. Fisheries Science 61: 628-636.

INTRIAGO P \& DA JONES (1993) Bacteria as food for Artemia. Aquaculture 113: 115-127.

IRIANTO A \& B AUSTIN (2002) Use of probiotics to control furunculosis in in rainbow trout, Oncorhynchus mykiss (Walbaum). Journal of Fish Disease 25: 333-342.

IRIANTO A \& B AUSTIN (2003) Use of dead probiotic cells to control furunculosis in rainbow trout, Oncorhynchus mykiss (Walbaum). Journal of Fish Disease 26: 59-62.

ISHIO S, RE MANGINDAAN, M KUWAHARA \& H NAKAGAWA (1989) A bacterium hostile to flagellates: identification of species and characters. En: Okaichi T, DM Anderson \& T Nemoto (eds) Red tides: biology, environmental science and toxicology: 205-208. Elsevier Science Publishing Co. Inc., New York, New York, USA.

ITURRIAGA R \& A ZSOLNAY (1983) Heterotrophic uptake and transformation of phytoplankton extracellular products. Botanica Marina 26: 375-386.

JAYANTH K, G JEYASEKARAN \& J SHAKILA (2001) Biocontrol of fish bacterial pathogens by the antagonistic bacteria isolated from the coastal water of Gulf of Mannas, India. Bulletin of the European Association of Fish Pathologists 21: 12-18.

JONES AK \& RC CANNON (1986) The release of miroalgal photosynthate and associated bacterial uptake and heterotrophic growth. British Phycological Journal 21: 341-358.

KELLAM SJ \& JM WALKER (1989) Antibacterial activity from marine microalgae in laboratory culture. British Phycological Journal 24: 191-194.

KELLAM SJ, RJP CANNELL, AM OWSIANKA \& JM WARKER (1988) Result of a large scale screening programme to detect antifungical activity from marine and freshwater microalgae in laboratory culture. British Phycological Journal 23: 45-47.

KENT ML (1992) Diseases of seawater netpen-reared salmonid fishes in the Pacific Northwest. Canadian Special Publication of Fisheries and Aquatic Sciences (Canada) 116: 18-19.

KIM M, I YOSHINAGA, I IMAI, K NAGASAKI, S ITAKURA \& Y ISHIDA (1998) A close relationship between algicidal bacteria an termination of Heterosigma akashiwo (Raphidophyceae) blooms in Hiroshima Bay, Japan. Marine Ecology Progress Series 170: $25-32$.

KOGURE K, U SIMIDU \& N TAGA (1979) Effect of Skeletonema costatum (Grev) Cleve on the growth of marine bacteria. Journal of Experimental Marine Biology and Ecology 36: 201-215.

KORMAS KA, K KAPIRIS, M THESSALOU-LEGAKI \& A NICOLAIDOU (1998) Quantative relationships between phytoplankton, bacteria and protests in an Aegean semi-enclosed embayment (Maliakos Gulf, Greece). Aquatic Microbial Ecology 15: 255-264.

LANDSBERG JH, KA STEIDINGER \& BA BLAKESLEY (1995) Fish-killing dinoflagellates in a tropical aquarium. En: Lassus P, G Arzul, E Erard-Le Denn \& P Gentienc (eds) Harmful marine algal blooms: 65-70. Marcaillou-Le Baut, Lavoisier, Paris, France.

LEMOS ML, AE TORANZO \& JL BARJA (1985) Antibiotic activity of epiphytic bacteria isolated from intertidal seaweeds. Microbial Ecology 11: 149-163. 
LE PENNEC M \& C RANGEL-DAVALOS (1985) Observation by epifluorescence microscopy of ingestion and digestion of unicellular algae by young larvae of Pecten maximus pectinidae bivalvia. Aquaculture 47: 39-52.

LODEIROS CJ, E FERNÁNDEZ, A VELEZ \& J BASTARDO (1988) Producción de antibióticos por bacterias marinas y su utilización en acuicultura. Boletín del Instituto Oceanográfico (Venezuela) 27: 63-69.

LORA-VILCHIS MC \& AN MAEDA-MARTÍNEZ (1997) Ingestión and digestión index of catarina scallop Argopecten ventricosus-circularis, Sowerby II, 1942, veliger larvae with ten microalgae species. Aquaculture Research 28: 905-910.

LOVEJOY C, JP BOWMAN \& GM HALLEGRAEFF (1998) Algicidal effects of a novel marine Pseudoalteromonas isolate (Class Proteobacteria, Gamma subdivision) on harmful algal bloom species of the genera Chattonella, Gymnodinium and Heterosigma. Applied and Environmental Microbiology 64: 2806-2813.

MAEDA M (1994) Biocontrol of the larvae rearing biotope in aquaculture. Bulletin of the National Research Institute of Aquaculture 1: 71-74.

MAEDA M \& K NOGAMI (1989) Some aspects of the biocontrolling method in aquaculture. En: Miyachi S, I Karube \& Y Ishida (eds) Current topics in marine biotechnology: 395-398. Japanese Society of Marine Biotechnology, Tokyo, Japan.

MALONE TC \& HW DUCKLOW (1990) Microbial biomass in the coasts plume of Chesapeake Bay: Phytoplankton-bacterioplankton relationship. Limnology and Oceanography 35: 296-312.

MUNRO PD, BARBOUR A \& TH BIRKBECK (1995) Comparison of the growth and survival and larval turbot in the absence of cultivable bacteria with dose in the presence of Vibrio anguillarum, Vibrio alginolyticus or a marine Aeromonas sp. Applied and Environmental Microbiology 61: 4425-4428.

NAAS KE, T NASS \& T HARBOE (1992) Enhanced first feeding of halibut larvae (Hippoglossus hippoglossus L) in green water. Aquaculture 105: 143-156.

NAIR S \& U SIMIDU (1987) Distribution and significance of heterotrophic marine bacteria with antibacterial activity. Applied and Environmental Microbiology 53: 2957-2962.

NAKAMURA A, GK TAKAHASHI \& K MORI (1999) Vibriostatic bacteria isolated from rearing seawater of oyster brood stock: Potentiality as biocontrol agents for vibriosis in oyster larvae. Fish Pathology 34: 139-144.

NAVINER M, JP BERGÉ, P DURAND \& H LE BRIS (1999) Antibacterial activity of marine diatom Skeletonema costatum against aquacultural pathogens. Aquaculture 174: 15-24.

NELL JA, DG MacLENNAN, GL ALLAN, SP NEARHOS \& J FRANCES (1994) Evaluation of new microbial food as partial substitutes for microalgae in a diet for Sydney rock oyster Saccostrea commercialis larvae and spat. En: Nell JA, DG MacLennan, GL Allan, SP Nearhos \& J Frances (eds) New microbial foods for aquaculture. Final Report to Fisheries Research Development Corporation, New South Wales Fisheries, Brackish Water Fish Culture Research Station, Salamander Bay, New South Wales, Australia. 98 pp.

NOGA EJ (1998) Toxic algae, fish kills and fish disease. Fish Pathology 33: 337-342.

NOGA EJ, SA SMITH, JM BURKHOLDER, C HOBBS \& RA BULLIS (1993) A new ichthyotoxic dinoflagellate: Cause of acute mortality in aquarium fishes. Veterinary Record 133: 96-97.

NOGAMI K \& M MAEDA (1992) Bacteria as biocontrol agents for rearing larvae of the crab Portunus trituberculatus. Canadian Journal of Fisheries and Aquatic Science 49: 2373-2376.

OHARA S, K FUKAMI \& Y ISHIDA (1993) Algal effects on the bacterial assemblage in Lake Biwa. Japanese Journal of Limnology 54: 261-268.

OLAFSEN JA (2001) Interactions between fish larvae and bacteria in marine aquaculture. Aquaculture 200: 223-247.

OLABI AO, ZC COB, DA JONES \& JW LATCHFORD (1999) Influence of algal exudates and bacteria on growth and survival of white shrimp larvae fed entirely on microencapsulated diets. Aquaculture International 7: 137-158.

OLSEN AI, Y OLSEN, Y ATTRAMADAL, K CHRISTIE, TH BIRKBECK, J SKJERMO \& O VADSTEIN (2000) Effects of short term feeding of microalgae on the bacterial flora associated with juvenile Artemia franciscana. Aquaculture 190: 11-25.

PAERL HW \& JL PINCKNEY (1996) A mini-review of microbial consortia. Their roles in aquatic production and biogeochemical cycling. Microbial Ecology 31: 225-247.

PESANDO D (1990) Antibacterial and antifungical activities of marine algae. En: Akatsuka I (ed) Introduction to applied phycology: 3-26. Balogh International Incorporated, Illinois, USA.

PRIEUR D, G MÉVEL, JL NICOLAS, A PLUSQUELLEC \& M VIGNEULLE (1990) Interactions between bivalve molluscs and bacteria in the marine environment. Oceanography Marine Biological Annual Review 28: 277-352.

RENSEL JE (1993) Severe blood hypoxia of Atlantic salmon (Salmo salar) exposed to the marine diatom Chaetoceros concavicornis. En: Smayda T \& Y Shimizu (eds) Toxic Phytoplankton Blooms in Sea: 625-630. Elsevier, New York, New York, USA.

RICO-MORA R \& D VOLTOLINA (1998) Biological control of Vibrio alginolyticus in Skeletonema costatum (Bacillariophyceae) culture. Aquaculture Engineering 19: 1-6

RICO-MORA R \& D VOLTOLINA (1995) Bacterial interactions in Skeletonema costatum Cleve (Bacillariophyceae) culture. Rivista Italiana Acquacoltura 30: 105-109.

RIEMANN L, GF STEWARD \& F AZAM (2000) Dynamics of bacterial community composition and activity during mesocosm diatom bloom. Applied and Environmental Microbiology 66: 578-587.

RIQUELME CE \& Y ISHIDA (1988) Chemotaxis of bacteria to extracellular products of marine bloom algae. Journal of General Applied Microbiology 34: 417-423.

RIQUELME CE, K FUKAMI \& Y ISHIDA (1987) Annual Fluctuations of phytoplankton and bacterial communities in Maizuru bay and their interrelationship. Bulletin of the Japanese Society of Microbial Ecology 2: 29-37.

RIQUELME CE, K FUKAMI \& Y ISHIDA (1988) Effect of bacteria on the growth of a marine diatom, Asterionella gracialis. Bulletin of Japanese Society of Microbial Ecology 3: 29-34.

RIQUELME C, R ARAYA \& R ESCRIBANO (2000) Selective incorporation of bacteria by Argopecten purpuratus larvae: implications for the use of probiotics in culturing systems of the Chilean scallop. Aquaculture 181: 25-36.

RIQUELME C, R ARAYA, N VERGARA, A ROJAS, M GUAITA \& M CANDIA (1997) Potential of 
probiotic strains in the culture of the Chilean scallop Argopecten purpuratus (Lamarck, 1819). Aquaculture 154: 17-26.

RIQUELME C, M JORQUERA, A ROJAS, R AVENDAÑO \& N REYES (2001) Addition of inhibitor-producing bacteria to mass culture of Argopecten purpuratus (Lamarck, 1819). Aquaculture 192: 111-119.

REICHEL JL \& MA BOROWITSKA (1984) Antimicrobial activity from marine algae: results of large scale screening programme. Hydrobiologia 116: 158-168.

ROBINSON W (1983) Quantification of ingestion by Mercenaria mercenaria (L) veligers feeding on mixed suspensions of inert material and algae using microspectrofluorimetry. Journal of Molluscan Studies (Supplement 12a): 167-171.

SAFFERMAN RS \& ME MORRIS (1962) Evaluation of natural products for algicidal properties. Applied Microbiology 10: 289-292.

SAKATA T (1990) Ocurrence of marine Saprospira sp. possessing algicidal activity for diatoms. Nippon Suisan Gakkaishi 56: 1165.

SALVESEN I, KI REITAN, J SKJERMO \& G ØIE (2000) Microbial environment in marine larviculture: Impact of algal growth rates on the bacterial load in six microalgae. Aquaculture International 8: 275-287.

SAMAIN JF, JC COCHARD, L CHEVELOT, JY DANIEL, C JEANTHON, JR LE COZ, Y MARTY, J MOAL, D PRIEUR \& M SALAUN (1987) Effect de la qualité de l' eau sur la croissance larvaire de Pecten maximus en écloserie: observations preliminaries. Haliotis 6: 363-381.

SERVAIS P \& G BILLEN (1993) Dynamic of heterotrophic bacteria in aquatic system: the HSB model. En: Guerrero G \& C Pedrós-Alió (eds) Trends in microbial ecology: 397-400. Spanish Society for Microbiology Publisher, Barcelona, Spain.

SHILO M (1970) Lysis of blue-green algae by a myxobacter. Journal of Bacteriology 104: 453-561.

SIEBURTH JMcN (1959) Antibacterial activity of Antarctic marine phytoplankton. Limnology and Oceanography 4: 419-424.

SIEBURTH JMcN (1971) An instance of bacterial inhibition in oceanic surface water. Marine Biology 11: $98-100$

SIMIDU U, E KANEKO \& N TAGA (1977) Microbiological studies of Tokyo Bay. Microbial Ecology 3: 173-191.

SHUMWAY SE (1990) A review of the effects of algal blooms on shellfish and aquaculture. Journal of the World Aquaculture Society 21: 65-104.

SKJERMO J \& O VADSTEIN (1993) Characterization of the bacterial flora of mass cultivated Brachionus plicatilis. Hydrobiologia 255-256: 185-191.

SUNDH I (1992) Biochemical composition of dissolved organic carbon derived from phytoplankton and used by hetrotrophic bacteria. Applied and Environmental Microbiology 58: 2938-2947.

SUTTLE CA (1994) The significance of viruses to mortality in aquatic microbial communities. Microbiology Ecology 28: 237-243.

SUTTLE CA (1993) Enumeration and isolation of viruses. En: Kemp PF \& JJ Cole (eds) Current methods in aquatic microbial ecology: 135-138. Lewis Publishers, London, England.

SUTTLE CA (1992) Inhibition of photosynthesis in phytoplankton by the submicron size fraction concentrated from seawater. Marine Ecology Progress Series 87: 105-112.

SUTTLE CA, AM CHAN \& MT COTTRELL (1990) Infection of phytoplankton by viruses and reduction of primary productivity. Nature 347: 467-469.

TARUTANI K, K NAGASAKI \& M YAMAGUCHI (2000) Viral impacts on total abundance and clonal composition of the harmful bloom-forming phytoplankton Heterosigma akashiwo. Applied and Environmental Microbiology 66: 4916-4920.

TENDENCIA EA \& M dela PEÑA (2003) Investigation of some component of green water system which makes it effective in the initial control of luminous bacteria. Aquaculture 218: 115-119.

TETTELBACH ST, LM PETTI \& MJ BLOGOSLAWSKI (1994) Survey of Vibrio associated with a New Haven Harbor shellfish bed, emphasizing recovery of larval oyster pathogens. En: Colwell RR (ed) Vibrios in the environment: 495-509. John Wiley \& Sons, New York, New York, USA.

VISO AC, D PESANDO \& C BABY (1987) Antibacterial and antifungal properties of some marine diatoms in culture. Botanica Marina 30: 41-45.

WESTERDAHL A., OLSSON J, KJELLEBERG S \& $\mathrm{P}$ CONWAY (1991) Isolation and characterization of Turbot (Scopthtalmus maximus) associated bacteria with inhibitory effects against Vibrio anguillarum. Applied and Environmental Microbiology 57: 2223-2228.

YOSHINAGA I, T KAWAI \& Y ISHIDA (1997) Analysis of algicidal ranges of the bacteria killing the marine dinoflagellate Gymnodinium mikimotoi isolated from Tanabe Bay, Wakayama Pref., Japan. Fisheries Science 63: 94-98.

YOSHINAGA I, T KAWAI \& Y ISHIDA (1995a) Lysis of Gimnodinium nagasakiense by marine bacteria. En: Lassus P, G Arzul, E Erard, P Gentien \& C Marcaillou (eds) Harmful marine algal blooms: 687-693. Lavoisier Publishing, Paris, France.

YOSHINAGA I, T KAWAI, T TAKEUCHI \& Y ISHIDA (1995b) Distribution and fluctuation of bacteria inhibiting the growth of a marine red tide phytoplankton Gymnodinium mikimotoi in Tanabe Bay (Wakayama Pref., Japan). Fisheries Science 61: 780-786. 